\title{
Alveolar Bone Loss with Microarchitecture Changes in Aged Rat
}

\author{
Pérdida Ósea Alveolar con Alteraciones en la Microarquitectura en Ratas Envejecidas
}

\author{
Yong Zheng' \& Nana Han ${ }^{2,3}$
}

\begin{abstract}
ZHENG, Y. \& HAN, N. Alveolar bone loss with microarchitecture changes in aged rat. Int. J. Morphol., 39(5):1443-1446, 2021.
SUMMARY: The aim of the present study was to evaluate the changes of alveolar bone in aged rats. The mandibles of the 4month and 22-month aged rats were scanned by micro-CT. After the reconstruction of the alveolar bone,the distance between the cemento enamel junction (CEJ) and the alveolar bone crest (ABC) was measured. The micro architectures of the inter-radicular alveolar bone were analyzed. The 22-month rats experienced the reduction in alveolar crest height in the buccal side and the lingual side, and significant increase in alveolar bone loss compared with the 4-month rats. The 22-month rats had a porous microarchitecture, the trabecular arrangement was obviously dissociated with the expanded inter-bone spaces of marrow, and the bone histomorphometry analysis showed the decreased bone volume/tissue volume and trabecular thickness in the 22-month rats. These results suggest that alveolar bone loss and alveolar trabecular bone deterioration might contribute to the weakening of molar support in the elderly.
\end{abstract}

KEY WORDS: Alveolar bone loss; Mandible; Micro-CT; Bone histomorphometry.

\section{INTRODUCTION}

Aging is associated with a progressive decline or loss of intrinsic physiological functions, which often lead to the numerous aging disorders (Campisi et al., 2019) Nowadays, seniors have more opportunities for dental treatment, it is essential to make efforts to preserve their teeth and maintain the masticatory function. Supportive and protective roles of the alveolar bone are very critical to sustain masticatory function (Kim et al., 2021). The alveolar bone undergoes physiological changes with age (Lovasova et al., 2018). Therefore, understanding the effect of aging on alveolar bone would be important to keep the masticatory function and further life quality in a good condition.

Alveolar bone is a component of the periodontium which support attachment for the tooth and help the tooth to endure the stress of mastication (Kim et al.). It has been reported that there is a relationship between oral bone loss and osteoporosis, while, the condition of systemic bone mass is associated with the periodontitis, which is a major factor in tooth loss in the elderly (Jeffcoat, 2005). Even though osteoporosis is becoming a public concern, the actual effect of osteoporosis on the alveolar bone remains vague.
Osteoporosis is a skeletal disorder characterized by compromised bone strength, predisposing the bone to an increased risk of fracture (Shah et al., 2018). Trabecular structural damage reflects the fragility of bone tissue, patients with osteoporosis shows changes of trabecular pattern in the jaw bone (Lee et al., 2019). For dental treatment of the elderly, it is essential to determine the effect of aging on the trabecular structure of the alveolar bone. Therefore, we assessed alveolar bone changes in aged rats. The understanding the effect of aging on alveolar bone would be beneficial to maintain the oral environment and the good quality of life.

\section{MATERIAL AND METHOD}

Animals. All animal procedures were performed under guidelines approved by the Tongji Hospital ofTongji Medical College Committees on Animal Experimentation. Twelve male Wistar rats, obtained from the experimental Animal Center of Hubei Province, were chosen randomly into two

\footnotetext{
${ }^{1}$ Department of Anatomy and Embryology, Wuhan University School of Basic Medical Sciences, Wuhan University, Wuhan, China. ${ }^{2}$ Department of Stomatology, Tongji Hospital, Tongji Medical College, Huazhong University of Science and Technology, Wuhan, China. ${ }^{3}$ School of Stomatology, Tongji Medical College,Huazhong University of Science and Technology, Wuhan, China.

FUNDING: National natural science foundation of China (81500844;81402296)
} 
groups. One group was sacrificed at age 4 months. The others were sacrificed at age 22 months. All rats were housed in filter-top cages in a temperature and humiditycontrolled room $\left(20-24^{\circ} \mathrm{C}\right.$ and $30-70 \%$, respectively) with a 12-hour light-dark cycle.

CT image acquisition and the assessment of the alveolar bone. The mandibles of the rats were excised gently and fixed in $4 \%$ paraformaldehyde for 48 hours. A microCT system (SkyScan1276, Kontich, Belgium) was used to evaluate the alveolar bone.The micro-CT parameters were as follows: slice thickness, $22 \mathrm{~mm}$; pixel size, $760 ¥ 760$; voltage, $50 \mathrm{kV}$; and electrical current, $200 \mathrm{~mA}$.

Three-dimensional models were generated by MIMICS 10 software (Materialize NV, Leuven, Belgium). The microstructure indicators of bone volume/ tissue volume (BV/TV), trabecular thickness (Tb. Th) and trabecular number $(\mathrm{Tb} . \mathrm{N})$ were determined using a region of interest (ROI) by Sky scan analysis software(CT Analyser, Skyscan, Belgium). According to a previous study (Xu et al., 2014), the ROI was a cuboidal bone body that encompassed the roots of the mandibular first molar.
With the help of the Mimics software, the distance between the cementoenamel junction (CEJ) and the alveolar bone crest $(\mathrm{ABC})$ was measured by the method reported previously. Six sites of the root surfaces of the first molars were measured, and the mean of the six values was calculated as the bone loss for each rat.

Statistical analysis. All data are presented as the means mean \pm standard deviation. The comparison among groups was performed bythe SNK multiple comparison test after a one-way ANOVA test, $\mathrm{p}<0.05$ was considered statistically significant.

\section{RESULTS}

CEJ-ABC distances in aged rat. According to the micro$\mathrm{CT}$ reconstruction of the alveolar bone, the CEJ-ABC distance of 22-month rats was $1.23 \mathrm{~mm}$, while the distance in 4-month rats was $0.95 \mathrm{~mm}$ (Fig. 1). The 22-month rats experienced the reduction in alveolar crest height, especially on the lingual alveolar bone. The results of this
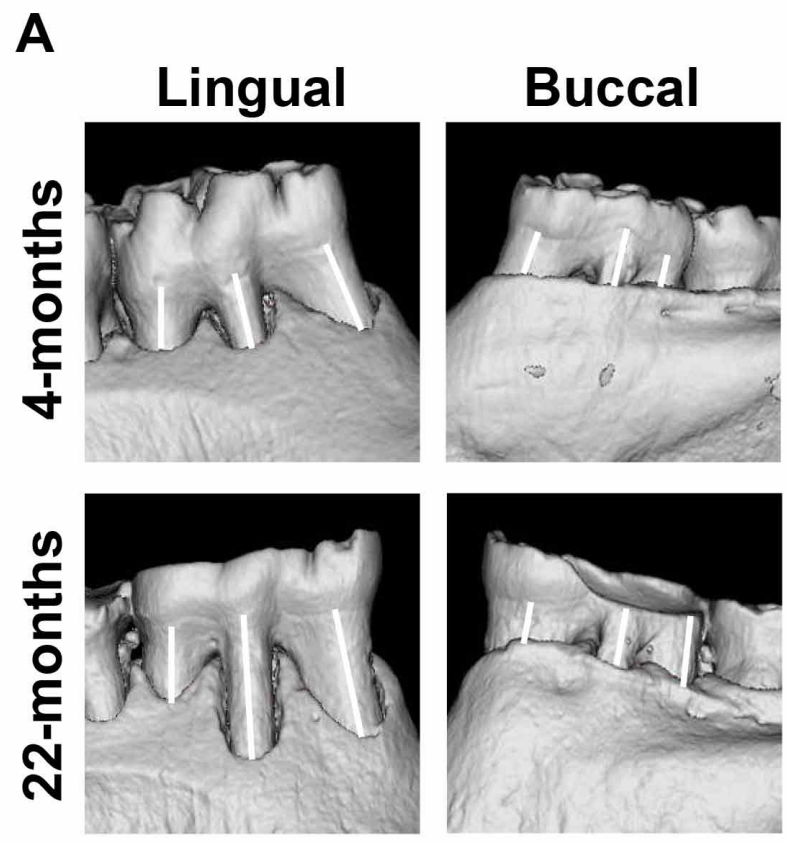

Fig. 1. Effect of aging on mandibular of cementoenamel junction (CEJ) to alveolar bone crest (ABC): a) The reconstructed threedimensional micro-CT images show buccal and lingual sides of the first mandibular molars. The distance from the CEJ to the $\mathrm{ABC}$ at six points is shown by the white lines; $(\mathrm{b}-\mathrm{d})$ Analysis of the CEJ-ABC distance at 4-months and 22-months rats. Data are expressed as the mean \pm the standard deviation $(\mathrm{N}=6$; * indicates $\mathrm{p}<0.05$, compared with 4 -months rats).
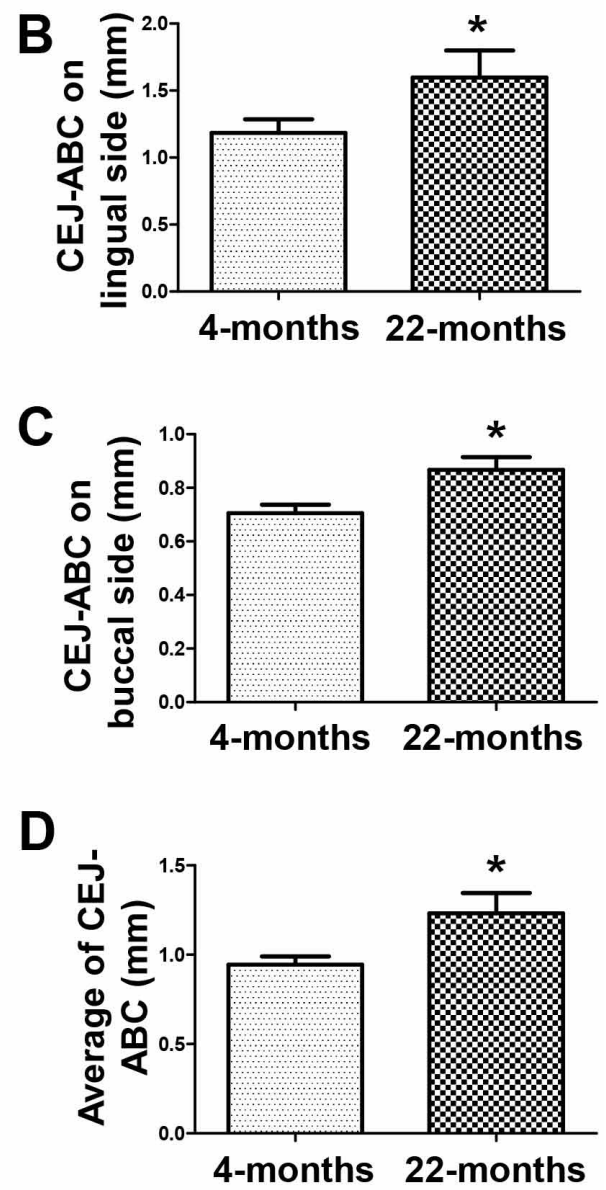
study demonstrated significant increases in alveolar bone loss in aged rats compared with the young rats.

Porotic changes of the alveolar bone. The micro architectures of the inter-radicular alveolar bone were also reconstructed with micro-CT images. In the interradicular septum of M1 alveolar bone of the 4-month rats, the trabeculae connected with each other and the bone trabecular was thick and the void space was very small. Comparing the compact structure of alveolar bone in 4month rats, the 22 -months rats had a porous micro architecture, the trabecular arrangement was obviously dissociated with the expanded inter-bone spaces of marrow (Fig. 2a).

The results of bone histomorphometry analysis revealed significant differences in BV/TV and Tb.Th. of the alveolar bone between 4-months and 22-months rats. 22-months rats were associated with decreased $\mathrm{BV} / \mathrm{TV}$ and Tb.Th compared to the 4-month rats (Figs. 2b,c). Trabecular number exhibited no significant differences among the groups (Fig. 2d). These results indicate deterioration of trabeculae of the alveolar bone in 22-month rats.
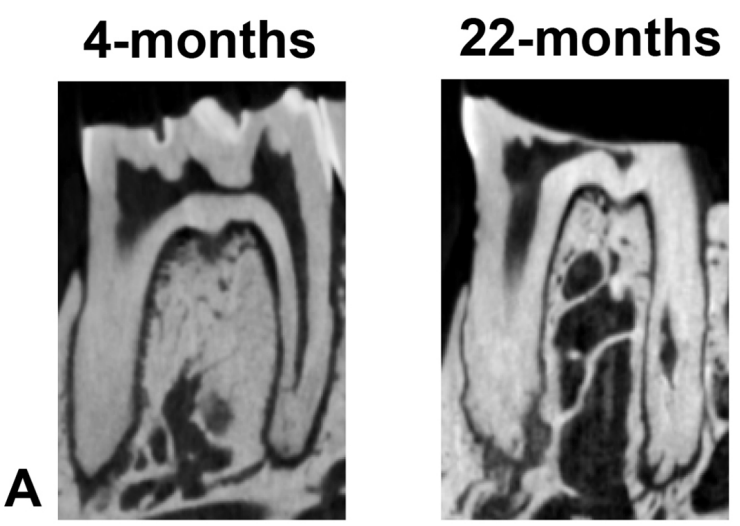

\section{DISCUSSION}

In recent decades, the elderly population is accelerating globally (Campisi et al.). This has resulted in an increase in the number of elderly patients who require treatment of the oral disease. Age associated changes of the alveolar bone need to be taken into consideration for the dental treatment (López et al., 2017). In this study, alveolar bones in 4-month and 22-month rats were evaluated by micro-CT. Alveolar bone loss was detected in the 22-month rats, this phenomenon was consistent with the age-related changes in mice (Rivaldo et al., 2005). These results indicated the alveolar bone in 22-month rats shows a weakening of support of the molars, and this finding was similar to human's alveolar bone profile in the elderly.

With aging, the most common systemic skeletal disease is osteoporosis which is characterized by low bone mass and deterioration of trabeculae (Rachner et al., 2011). In rat long bones, the bone mass decreases with age in both genders (Lelovas et al., 2008). For the changes of the alveolar bone, BV/TV, as a parameter used to describe bone mass, was reduced significantly in 22-month rats compared to 4month rats. In addition to the comparation with bone mass, changes in micro architecture were investigated to evaluate the quality of alveolar bonein 4-month and 22-month rats. In the present study, decreased values of Tb.Th in 22-month rats indicated thinning of the trabecular structure due to aging, which was a reason for the BV/TV reduction. These results suggest that the reduction of bone mass and deterioration of the trabeculae of alveolar bone resulted from the aging in rats.

It is known that the deterioration of trabecular structure was difficult to restore (Harris et al., 2020), the more studies on the mechanisms underlying the age-related
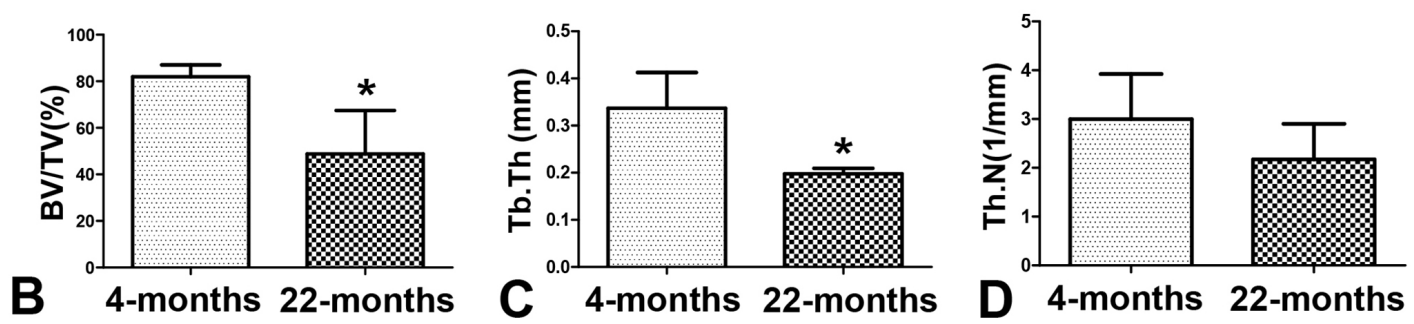

Fig. 2. Effect of aging on mandibular by analysis of bone volumetric parameters: a) The interradicular septum between the medial and distal roots of the first molar in the mandibular; (b-d) Analysis of micro-CT volumetric parameters at 4-months and 22-months rats; bone volume/tissue volume (BV/TV), trabecular thickness (Tb.Th), and trabecular number (Th.N). Data are expressed as the mean \pm the standard deviation $(\mathrm{N}=6$; * indicates $\mathrm{p}<$ 0.05 , compared with 4-months rats). 
trabeculae changes of alveolar bone should be carried out. The alveolar bone of rats had similar profiles to humans in terms of the trabecular structure deterioration with aging, the aged rats have a possibility to use as an adequate laboratory animal model for alveolar bone research in an aged population

\section{CONCLUSION}

This study evaluated the changes of alveolar bone in aged rats. In the 22-month rats, alveolar bone loss, reduction of bone mass and deterioration of the bone trabeculae were detected. These changes might be the reason for the weakening of molar support in the elderly, and showed the possibility to use the aged rats as animal model for alveolar bone research in an aged population.

ZHENG, Y. \& HAN, N. Pérdida ósea alveolar con alteraciones en la microarquitectura en ratas envejecidas. Int. J. Morphol., 39 (5):1443-1446, 2021

RESUMEN: El objetivo del presente estudio fue evaluar los cambios del hueso alveolar en ratas envejecidas. Las mandíbulas de las ratas de 4 y 22 meses se escanearon mediante micro-TC. Después de la reconstrucción del hueso alveolar, se midió la distancia entre la unión cementoesmalte (CEJ) y la cresta ósea alveolar (ABC) .Se analizaron las microarquitecturas del hueso alveolar interradicular. Las ratas de 22 meses experimentaron la reducción de la altura de la cresta alveolar. en el lado bucal y lingual, y un aumento significativo en la pérdida de hueso alveolar en comparación con las ratas de 4 meses. Las ratas de 22 meses tenían una microarquitectura porosa, la disposición trabecular estaba obviamente disociada con los espacios interóseos expandidos de la médula y el análisis de histomorfometría ósea mostró una disminución del volumen óseo / volumen tisular y del grosor trabecular en las ratas de 22 meses. Estos resultados sugieren que la pérdida ósea alveolar y el deterioro del hueso trabecular alveolar podrían contribuir al debilitamiento del soporte molar en los ancianos.

PALABRAS CLAVE: Pérdida de hueso alveolar; Mandíbula; Micro-CT; Histomorfometría ósea.

\section{REFERENCES}

Campisi, J.; Kapahi, P.; Lithgow, G. J.; Melov, S.; Newman, J. C. \& Verdin, E. From discoveries in ageing research to therapeutics for healthy ageing. Nature, 571(7764):183-92, 2019.

Harris, D.; Garrett, K.; Uppuganti, S.; Creecy, A. \& Nyman, J. S. The BALB/ $\mathrm{c}$ mouse as a preclinical model of the age-related deterioration in the lumbar vertebra. Bone, 137:115438, 2020.

Jeffcoat, M. The association between osteoporosis and oral bone loss. $J$. Periodontol., 76(11 Suppl.):2125-32, 2005.
Kim, Y. G.; Lee, S. M.; Bae, S.; Park, T.; Kim, H.; Jang, Y.; Moon, K.; Kim, H.; Lee, K.; Park, J.; et al. Effect of aging on homeostasis in the soft tissue of the periodontium: a narrative review. J. Pers. Med., 11(1):58, 2021.

Lee, C.; Lee, J. H.; Han, S. S.; Kim, Y. H.; Choi, Y. J.; Jeon, K. J. \& Jung, H. I. Site-specific and time-course changes of postmenopausal osteoporosis in rat mandible: comparative study with femur. Sci. Rep., 9(1):14155, 2019

Lelovas, P. P.; Xanthos, T. T.; Thoma, S. E.; Lyritis, G. P. \& Dontas, I. A. The laboratory rat as an animal model for osteoporosis research. Comp. Med., 58(5):424-30, 2008.

López, R.; Smith, P. C.; Göstemeyer, G. \& Schwendicke, F. Ageing, dental caries and periodontal diseases. J. Clin. Periodontol., 44 Suppl. 18:S145S152, 2017.

Lovasova, K.; Kachlik, D.; Rozpravkova, M.; Matusevska, M.; Ferkova, J. \& Kluchova, D. Three-dimensional CAD/CAM imaging of the maxillary sinus in ageing process. Ann. Anat., 218:69-82, 2018.

Rachner, T. D.; Khosla, S. \& Hofbauer, L. C. Osteoporosis: now and the future. Lancet, 377(9773):1276-87, 2011

Rivaldo, E. G.; Padilha, D. P. \& Hugo, F. N. Alveolar bone loss and aging: a model for the study in mice. J. Periodontol., 76(11):1966-71, 2005.

Shah, F. A.; Stoica, A.; Cardemil, C. \& Palmquist, A. Multiscale characterization of cortical bone composition, microstructure, and nanomechanical properties in experimentally induced osteoporosis. $J$. Biomed. Mater. Res. A., 106(4):997-1007, 2018.

Xu, X. C.; Chen, H.; Zhang, X.; Zhai, Z. J.; Liu, X. Q.; Qin, A. \& Lu, E. Y. Simvastatin prevents alveolar bone loss in an experimental rat model of periodontitis after ovariectomy. J. Transl. Med., 12:284, 2014.

Corresponding author:

Dr. Nana Han

Department of Stomatology

Tongji Hospital, Tongji Medical College

No. 1095, Jiefang Avenue

Wuhan

Hubei 430030

CHINA

E-mail: hnn0536@163.com

Received: 31-05-2021

Accepted: 06-07-2021 